\title{
Transition and heavy metals compared to oxidative parameter balance in patients with deep vein thrombosis: A case-control study
}

\author{
MARGHERITA FERRANTE ${ }^{1}$, MARIA FIORE ${ }^{1}$, GEA OLIVERI CONTI ${ }^{1}$, VALERIO FIORE ${ }^{2}$, \\ ALFINA GRASSO $^{1}$, CHIARA COPAT ${ }^{1}$ and SALVATORE SANTO SIGNORELLI ${ }^{2}$ \\ Departments of ${ }^{1}$ Medical, Surgical and Advanced Technologies 'G.F. Ingrassia' \\ and ${ }^{2}$ Clinical and Experimental Medicine, University of Catania, I-95123 Catania, Italy
}

Received December 30, 2016; Accepted February 3, 2017

DOI: $10.3892 / \mathrm{mmr} .2017 .6394$

\begin{abstract}
Our study compared copper $(\mathrm{Cu})$, zinc $(\mathrm{Zn})$ and manganese $(\mathrm{Mn})$, crucial for human normal physiology maintenance, and lead $(\mathrm{Pb})$ levels as environmental pollutant, in subjects suffering of deep vein thrombosis of lower limbs (DVTs) vs. healthy subjects. Furthermore, we evaluated oxidative stress parameters, the thiobarbituric acid reactive substances (TBARS) as the sum of malondialdehyde or 1,1,3,3-tetraethoxypropane (MDA) and 4-hydroxynonenal 4-HNE) and cytosolic superoxide dismutase (Cu/Zn-SOD) concentrations in both groups. We recruited 24 DVT cases and 46 healthy subjects as controls. Questionnaire with socio-demographic, habits and lifestyle were collected. Hair concentrations of $\mathrm{Zn}, \mathrm{Mn}, \mathrm{Cu}$ and $\mathrm{Pb}$ were measured by ICP-MS, plasma concentrations of MDA and 4-HNE were measured by HPLC and SOD plasma concentrations were detected by ELISA test. A quantitative and qualitative variables comparison between cases and controls group was made by Mann-Whitney U test and Pearson's Chi-square test, respectively. We found low concentrations of $\mathrm{Zn}, \mathrm{Mn}$ and $\mathrm{Cu}$ vs. high $\mathrm{Pb}$ concentrations in DVTs subjects. TBARS were found higher in the cases group, conversely, SOD concentrations were found lower in cases with respect to controls. Furthermore, we found the diet of pathological subjects significantly deficient in vegetables. These results are indicative of a lower enzymatic activity in patients, related to low transition metal levels in the DVTs and high levels of $\mathrm{Pb}$, coupled with an unbalanced diet.
\end{abstract}

\section{Introduction}

Deep vein thrombosis (DVTs) is the third most common cardiovascular disease (CVD) after ischemic heart disease

Correspondence to: Dr Chiara Copat, Department of Medical, Surgical and Advanced Technologies 'G.F. Ingrassia', University of Catania, Via Santa Sofia 87, I-95123 Catania, Italy

E-mail:ccopat@unict.it

Key words: metals, DVTs, oxidative stress, oxidative balance, $\mathrm{diet} /$ vegetables and stroke (1). The determinant factors for DVTs also include environmental factors such as exposure to atmospheric pollution (2-5), genetic factors (6) and unbalanced lifestyle habits, such as poor diet (7-9), physical inactivity, smoking and alcohol consumption (10). The risk for human health derived from an unbalanced diet, can lead to a deficiency of essential metals. Essential trace elements are those compounds that need to be present in the human diet to maintain normal physiological functions. Copper $(\mathrm{Cu})$, manganese $(\mathrm{Mn})$ and zinc $(\mathrm{Zn})$ have been recognized as essential elements due to their presence in important proteins and enzymes such as pyruvate carboxylase and SOD (11).

Conversely, others metals such as lead $(\mathrm{Pb})$, iron $(\mathrm{Fe})$, chromium $(\mathrm{Cr})$ and cobalt $(\mathrm{Co})$ undergo cycling reactions and have the possibility to produce reactive oxygen species (ROS) in biological systems. Therefore, disruption of metal ion homeostasis may lead to oxidative stress that induces DNA damage, lipid peroxidation and protein modification. This leads to numerous diseases, including cancer, cardiovascular disease, diabetes, atherosclerosis, venous thromboembolism, neurological disorders, chronic inflammation and others. The mechanism of action for all these metals involves formation of the ROS, finally producing malondialdehyde (MDA), 4-hydroxynonenal (4-HNE) and metabolic consumption of antioxidant species such as SOD (12).

Our study compared the essential elements $\mathrm{Cu}, \mathrm{Zn}$ and $\mathrm{Mn}$, crucial for normal physiology maintenance, and $\mathrm{Pb}$ levels as environmental pollutant, in hair of subjects suffering of deep vein thrombosis of lower limbs (DVTs) vs. healthy subjects. Furthermore, we evaluated oxidative stress parameters, the thiobarbituric acid reactive substances (TBARS) as the sum of malondialdehyde or 1,1,3,3-tetraethoxypropane (MDA) and 4-hydroxynonenal (4-HNE) and cytosolic superoxide dismutase $(\mathrm{Cu} / \mathrm{Zn}-\mathrm{SOD})$ plasma concentration in both groups.

\section{Materials and methods}

Study design. The study was based on a case-control design. The participants were recruited by the Department of Clinic and Experimental Medicine, University of Catania. The study 
was approved by the Ethics Committee 'Catania 1' and a written informed consent was obtained from each participant.

The socio-demographic, habits and lifestyle data were collected via questionnaire. Cases included in the study were selected by the following criteria: subjects with clinically diagnosed DVTs with increased volume limb, erythematosus skin tone (sometimes cyanotic), hot and glossy skin, sign of the fovea, pain after muscle strain, DVTs confirmed instrumentally; subjects with asymptomatic DVTs instrumentally diagnosed.

Some cases were excluded from the study with the following criteria: subjects aged $>75$ years and suffering of active chronic diseases; subjects with recently surgical procedures; subjects with a history of congenital thrombophilia; subjects with tattoos, metal joint implants and metal dentures; subjects with treated hair (permanent and color).

Sampling of hair and blood. Samples of hair were collected for analysis of transition metals $\mathrm{Cu}, \mathrm{Mn}$ and $\mathrm{Zn}$ and toxic metal $\mathrm{Pb}$, because easily accessible samples, available in sufficient quantities, non-invasive sampling and stable material that does not require special treatments. In addition, minerals do not deteriorate or disappear after collection.

Hair was cut with a stainless steel pair of scissors, which were cleaned and visually inspected between samples to prevent cross-contamination. Hair was collected in three strands from the left, central and right area of the nape. The first $3 \mathrm{~cm}$ next to the hairline were selected for metal determination, accurately washed into $50 \mathrm{ml}$ of falcon tube (Thermo Fischer Scientific, Pittsburgh, PA, USA) with bi-distilled water until water did not appear clean. Samples were then stored at $-20^{\circ} \mathrm{C}$ until processing.

Blood sample for TBARS and SOD analysis was collected by venipuncture, immediately centrifuged at $1,500 \mathrm{x} \mathrm{g}$ for $10 \mathrm{~min}$ at $4^{\circ} \mathrm{C}$ to separate the plasma. Plasma was then preserved in amber vials (Eppendorf AG, Hamburg, Germany) and stored at $-80^{\circ} \mathrm{C}$ until analysis.

Analysis of the metals. For metal extraction and quantification, aliquots of $0.5 \mathrm{~g}$ of each hair sample was weighed. An acid digestion was conducted with an Ethos TC microwave system (Milestone, Sorisole, Italy) with $6 \mathrm{ml}$ of $65 \%$ nitric acid $\left(\mathrm{HNO}_{3}\right)($ Carlo Erba, Milan, Italy) and $2 \mathrm{ml}$ of $30 \%$ peroxide hydrogen $\left(\mathrm{H}_{2} \mathrm{O}_{2}\right)$ (Carlo Erba) for $50 \mathrm{~min}$ operation cycle at $200^{\circ} \mathrm{C}$. After the cycle, at a temperature $<25^{\circ} \mathrm{C}$ the Teflon vessels (Milestone, Sorisole, Italy) were opened and Milli-Q water (Q-Gard ${ }^{\circledR} 1$; Merck Millipore, Darmstadt, Germany) was added to the samples up to $50 \mathrm{ml}$; an ICP-MS (ELAN ${ }^{\circledR}$ DRC-e; PerkinElmer, Inc., Waltham, MA, USA) was used for metal quantification. Standards for the instrument calibration were prepared with mono element certified reference solution ICP standard (Merck Millipore, Darmstadt, Germany). To validate analysis we spiked real samples in duplicate with $5 \mu \mathrm{g} / \mathrm{l}$ of each element, and the percentage of recovery ranged between 97.8 and $113.8 \%$. The method detection limits (MDL) estimated with $3 \sigma$ of the procedure blanks were (mg/kg w.w.): $\mathrm{Cu} 0.02$, Mn 0.25, Zn 0.10 and $\mathrm{Pb} 0.011$.

TBARS evaluation. TBARS were evaluated as the sum of MDA and 4-HNE concentrations according to the methodology previously described $(13,14)$.
Briefly, $125 \mu \mathrm{l}$ of thiobarbituric acid (TBA) $(0.25 \mathrm{~g}$ in $50 \mathrm{ml} \mathrm{H} \mathrm{H}_{2} \mathrm{O}$; Sigma-Aldrich St. Louis, MO, USA), $150 \mu \mathrm{l}$ HPLC-grade $\mathrm{H}_{2} \mathrm{O}$, and $325 \mu \mathrm{l}$ phosphoric acid $\left(\mathrm{H}_{3} \mathrm{PO}_{4}, 0.15 \mathrm{M}\right.$; Sigma-Aldrich) were added to $100 \mu \mathrm{l}$ plasma (in EDTA blood vials). The sample was incubated at $45^{\circ} \mathrm{C}$ for $1 \mathrm{~h}$ for 4 -HNE TBA derivatization and $90^{\circ} \mathrm{C}$ for $1 \mathrm{~h}$ for MDA, then placed in ice for $4 \mathrm{~min}$ and centrifuged at $1,500 \mathrm{x} \mathrm{g}$ for $10 \mathrm{~min}$ at $4^{\circ} \mathrm{C}$ and syringe-filtered $(0.45 \mathrm{~mm}$; Superchrom S.r.l., Milan, Italy). Twenty microliters of the sample was then successively injected in HPLC (Series 200; Perkin-Elmer, Inc., Waltham, MA, USA) equipped with a UV detector, and a fluorescence detector using a Lichrospher ${ }^{\circledR} 100$ RP-18 $(250 \times 4 \mathrm{~mm})$ column. The HPLC setting was: mobile phase consisting of $200 \mathrm{ml}$ methanol and $300 \mathrm{ml}$ phosphate-buffered saline ( $50 \mathrm{mM}, \mathrm{pH}$ 7.4) with a flow of $1.0 \mathrm{ml} / \mathrm{min}$ and detection was carried out using an excitation of $532 \mathrm{~nm}$ and an emission of $553 \mathrm{~nm}$. The calibration curve was carried out using commercial MDA (purity $>96 \%$; Merck Millipore) and 4-HNE (purity $>99 \%$, Cayman Chemical Co., Ann Arbor MI, USA) external standards, the calibration (five points) was performed using a pre-column derivatization with TBA. Mean recoveries of spiked matrices were 92 and $103 \%$ for MDA e 4-HNE, respectively. The MDL were $0.02 \mu \mathrm{M}-\mathrm{L}$ for MDA and $0.01 \mu \mathrm{M}-\mathrm{L}$ for 4-HNE.

SOD analysis. SOD was dosed in plasma (EDTA) samples using a certificate assay kit of Cayman Chemical Co. (Ann Arbor kits, MI 48108). SOD activity was assessed by measuring the dismutation of superoxide radicals generated by xanthine oxidase and hypoxanthine in a 96-well plate. A SOD unit (U) is defined as the amount of enzyme required to the $50 \%$ of dismutation. In our study, cytosolic $\mathrm{Cu}-\mathrm{Zn}$-SOD was detected. Briefly, the plasma was centrifuged at $1,500 \mathrm{x}$ g for $10 \mathrm{~min}$ at $4^{\circ} \mathrm{C}$. We collected only the top yellow plasma layer without disturbing the white buffy layer. The samples were diluted 1:5 with the equipped sample buffer. Sample processing and plate development were carried out according to the manufacturer's instructions. The plates were read at $440 \mathrm{~nm}$ through a Multiskan $^{\mathrm{TM}}$ Thermo Fisher spectrophotometer (Thermo Fisher Scientific, Inc., Waltham, MA, USA) for 96-well plates. MDL was $0.005 \mathrm{U} / \mathrm{ml}$.

Statistical analysis. Data were analyzed using SPSS, version 20.0 (SPSS, Inc., Chicago, IL, USA). The differences in the proportions of cases and controls responding to each question were tested by the Chi-square test. The Mann-Whitney $\mathrm{U}$ test was used to compare all quantitative variables between cases and controls. Results are presented as percentages and the corresponding p-value and as medians and interquartile range (IQR).

\section{Results}

Seventy volunteers (24 cases and 46 controls) were included in the study. Volunteers were males and females aged between 43 and 71 years, residents in the province of Catania. The small number of participants was due to the limited prevalence of the DVTs (2-4\% of the population) and it is frequently asymptomatic. In Tables I and II are summarized the results obtained from the administered questionnaires. Among the subjects recruited, there is a prevalence of women 
Table I. Frequencies of some qualitative variables stratified by cases and controls.

\begin{tabular}{|c|c|c|c|}
\hline Variables & $\begin{array}{l}\text { Cases } \\
\mathrm{n}(\%)\end{array}$ & $\begin{array}{c}\text { Controls } \\
\mathrm{n}(\%)\end{array}$ & P-value ${ }^{a}$ \\
\hline Gender & & & $<0.05$ \\
\hline Male & $17(70.8)$ & $20(43.5)$ & \\
\hline Female & $7(29.2)$ & $26(56.5)$ & \\
\hline Sport & & & 0.764 \\
\hline Yes & $8(33.3)$ & $17(37)$ & \\
\hline No & $16(66.7)$ & $29(63)$ & \\
\hline Smoking habits & & & 0.252 \\
\hline Current smokers & $6(25)$ & $13(28.3)$ & \\
\hline Never smoked & $9(37.5)$ & $24(52.2)$ & \\
\hline Ex-smokers & $9(37.5)$ & $9(19.6)$ & \\
\hline Drinking water type & & & 0.277 \\
\hline Mineral & $14(58.3)$ & $32(69.6)$ & \\
\hline Tap water & $10(41.7)$ & $12(26.1)$ & \\
\hline Both & 0 & $2(4.3)$ & \\
\hline Fruit consumption & & & 0.400 \\
\hline Yes & $16(66.7)$ & $35(76.1)$ & \\
\hline No & $8(33.3)$ & $11(23.9)$ & \\
\hline Vegetables consumption & & & $<0.001$ \\
\hline Yes & $9(37.5)$ & $39(84.8)$ & \\
\hline No & $15(62.5)$ & $7(15.2)$ & \\
\hline Fish consumption & & & 0.314 \\
\hline Yes & $10(41.7)$ & $25(54.3)$ & \\
\hline No & $14(58.3)$ & $21(45.7)$ & \\
\hline Alcohol consumption & & & 0.100 \\
\hline Yes & $7(29.2)$ & $6(13)$ & \\
\hline No & $17(70.8)$ & $40(87.0)$ & \\
\hline Mineral supplements use & & & 0.874 \\
\hline Yes & $4(16.7)$ & $7(15.2)$ & \\
\hline No & $20(83.3)$ & $39(84.8)$ & \\
\hline Herbal products use & & & 0.304 \\
\hline Yes & $2(8.3)$ & $8(17.4)$ & \\
\hline No & $22(91.7)$ & $38(82.6)$ & \\
\hline Hair products use & & & 0.229 \\
\hline Yes & $11(45.8)$ & $28(60.9)$ & \\
\hline No & $13(54.2)$ & $18(39.1)$ & \\
\hline Cosmetics use & & & 0.126 \\
\hline Yes & $7(29.2)$ & $21(45.7)$ & \\
\hline No & $17(70.8)$ & $22(47.8)$ & \\
\hline
\end{tabular}

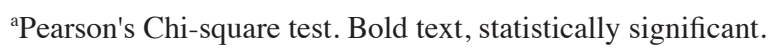

in the control group. Among the other socio-demographic parameters, habits and lifestyles, there is no association between case and control groups. According to the diet, it was revealed that the cases consumed fewer vegetables than the controls $(\mathrm{p}<0.001)$.

With regard to metal concentrations detected in hair sample, as shown in Fig. 1, the overall trend is a lower concentration of essential metals $\mathrm{Cu}, \mathrm{Mn}$ and $\mathrm{Zn}$ in the hair of subjects suffering of DVTs with respect to the control one. We found the median concentrations $9.52,0.090$ and $172 \mathrm{mg} / \mathrm{kg}$,
Table II. Distribution of some quantitative variables stratified by cases and controls.

\begin{tabular}{lccc}
\hline Variables & $\begin{array}{c}\text { Cases } \\
\text { median (IQR) }\end{array}$ & $\begin{array}{c}\text { Controls } \\
\text { median (IQR) }\end{array}$ & P-value $^{\mathrm{a}}$ \\
\hline Age & $64(52-71)$ & $54(43-66.8)$ & 0.201 \\
Weight $(\mathrm{kg})$ & $74(59.5-89.3)$ & $71.5(61.8-77.3)$ & 0.310 \\
Height $(\mathrm{m})$ & $1.65(1.57-1.75)$ & $1.65(1.60-1.71)$ & 0.598 \\
Liters of drinking & $1(1-2)$ & $1(1-2)$ & 0.702 \\
water per day & & & \\
\hline
\end{tabular}

${ }^{a}$ Mann-Whitney U test. IQR, interquartile range.

respectively, in the cases and $11.9,0.227$ and $182.5 \mathrm{mg} / \mathrm{kg}$ in the control group.

Conversely, the highest levels of the toxic metal $\mathrm{Pb}$ were found in the cases group ( $0.684 \mathrm{vs} .0 .297 \mathrm{mg} / \mathrm{kg}$ ). Although results indicate a clear pattern of accumulation between cases and control groups, statistically significant differences are related only to $\mathrm{Mn}(\mathrm{p}=0.011)$ and $\mathrm{Pb}(\mathrm{p}=0.042)$ concentrations.

With regard to oxidative stress parameters (Fig. 2), we found significantly higher median values in the cases than the control group for MDA ( 2.49 vs. $1.01 \mu \mathrm{M} / 1 ; \mathrm{p}<0.001)$ and TBARS (5.39 vs. $1.16 \mu \mathrm{M} / 1 ; \mathrm{p}<0.001$ ), as well as for 4-HNE ( 0.26 vs. $0.15 \mu \mathrm{M} / \mathrm{l})$; however, only 4 -HNE was without a significant $p$-value ( $\mathrm{p}=0.330$ ) (Fig. 2). Conversely, the antioxidant enzyme SOD was found higher in the control group than in the cases ( 5.92 vs. $4.37 \mathrm{U} / \mathrm{ml})$, but without significance $(\mathrm{p}=0.117)$. These results, even without strong statistical significance, indicate a status of oxidative stress in DVT subjects as well as deficiency in the oxide reductive system.

\section{Discussion}

Subjects with DVTs were recruited to evaluate bioaccumulation of essential metals $(\mathrm{Cu}, \mathrm{Mn}$ and $\mathrm{Zn})$. The toxic metal $\mathrm{Pb}$ can be a determinant factor in DVTs, and at which level the antioxidant defense system can be altered. In particular, the MDA, TBARS and 4-HNE levels, which are products of lipid peroxidation, were used as surrogate oxidation markers. A parameter reflecting antioxidant defenses measured in our study was $\mathrm{Cu} / \mathrm{Zn}$-SOD.

The status of oxidative stress occurs when the balance between the production of ROS and the antioxidant defense system is lacking. This imbalance can cause various diseases, including CVDs, thus DVTs. The endothelial integrity may therefore be less in case of excess of ROS or deficiency of antioxidant defense enzymes. The enzymes reduce the activity of ROS, and are able to maintain at vessel level the vasodilatory effects of nitric oxide (NO), conversely, ROS species can decrease the biological activity of NO (15), produced in the respiratory tract as part of the inflammatory process (16).

In several systemic diseases with an inflammatory component (cardiovascular, pulmonary, hepatic, retinal, and neurodegenerative), the products of lipid peroxidation are detected. The oxidation markers MDA and 4-HNE are among 

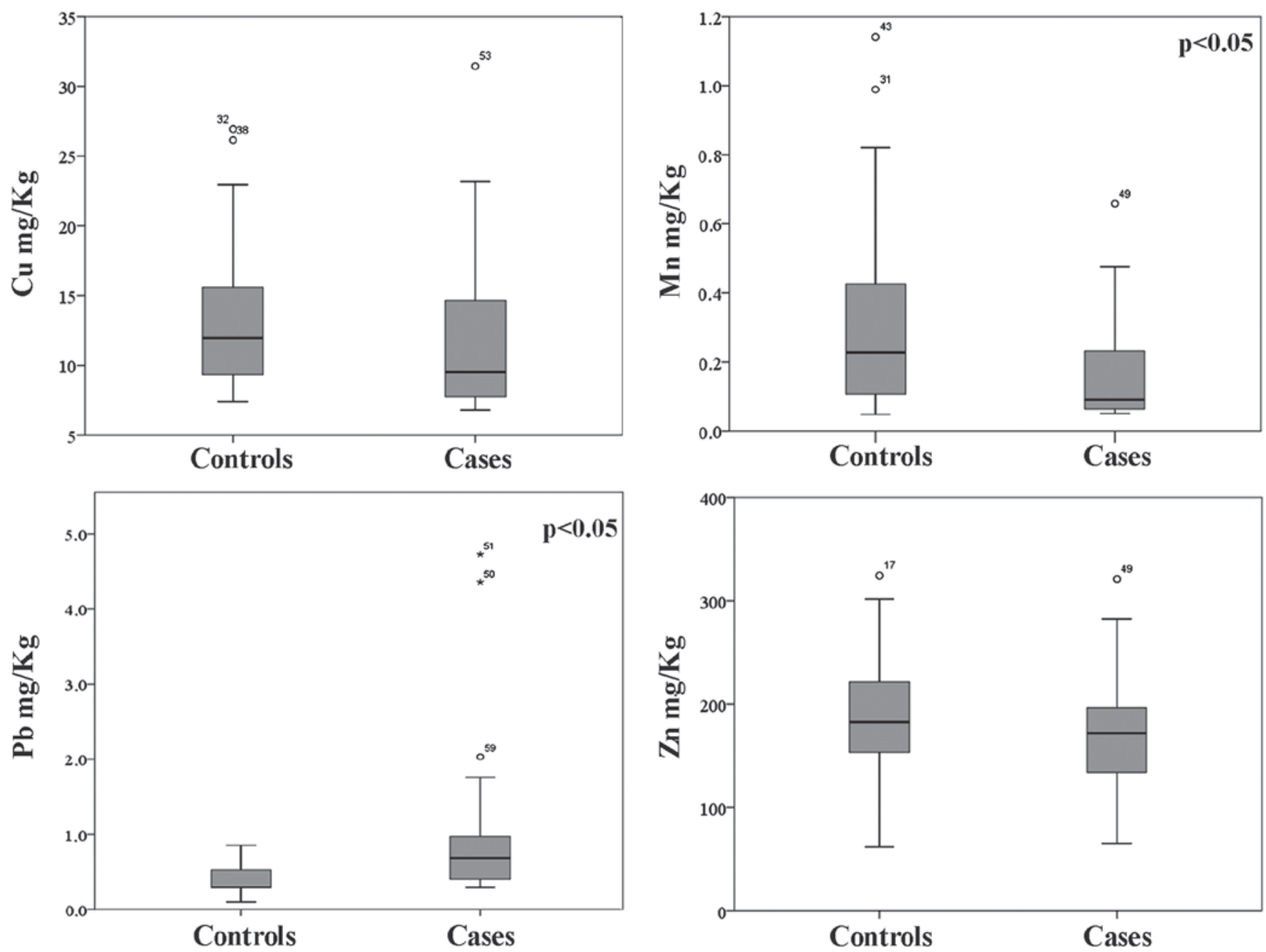

Figure 1. Box-plot of metal concentrations detected in hair samples of the cases and the control group.

the breakdown products most commonly used to validate index of oxidative stress (17). These products are relatively long-lived compared to ROS, forming covalent adducts with target molecules such as proteins, with important pathophysiological consequences (18).

Our findings show higher oxidative stress parameters in DVTs compared to controls, indicating a physiological condition of oxidative stress, but highlighting significant differences only for MDA and TBARS. Low concentration of 4-HNE was detected in all subjects, while in the cases, it was found slightly higher. These results could be explain by the normal 4-HNE generation only amounting to $10 \%$ of that of MDA, as demonstrated in several in vitro oxidation studies (19).

The first line of enzymatic defense against oxidative stress is represented by the antioxidant enzyme SOD, and to a lesser extent by other enzymes such as ubiquinone oxidoreductase and catalase (NADH) (20). In particular, SOD catalyzes the dismutation of superoxide radicals into hydrogen peroxides $\left(\mathrm{H}_{2} \mathrm{O}_{2}\right)$ and prevents the $\mathrm{NO}_{2}$ and peroxinitrites formation $(21,22)$. Deficit of some essential metals ( $\mathrm{Cu}, \mathrm{Zn}$ and $\mathrm{Mn}$ ) may be the determinant of the reduction of SOD activity. It is known that $\mathrm{Cu} / \mathrm{Zn}-\mathrm{SOD}$ and not Mn-SOD is inactivated, at a temperature of $37^{\circ} \mathrm{C}$ and a $7.4 \mathrm{pH}$, in the presence of $\mathrm{H}_{2} \mathrm{O}_{2}$ and superoxide ion $(23,24)$. In a healthy status, platelets possess high levels of the SOD, in particular, $77 \%$ of $\mathrm{Cu} / \mathrm{Zn}$-SOD and the remaining part of Mn-SOD (25), thus, SOD plays and important role in the platelet membrane fluidity and in the prevention of thrombosis. Our results highlight lower concentrations of the essential metals in DVTs, especially Mn that is significantly lower in this group. As said before, these metals are above all, essential to activate the SOD antioxidant defense, and we found a decreased activity of this enzyme in the DVT groups; SOD adds to the increased production of surrogate oxidative markers.

As indicated by the analysis of the questionnaries, there are no significant differences among socio-demographics, habits and lifestyle parameters, except for vegetable consumption, lower in the controls group, justifying, even if only in part, the increase of the oxidative stress in DVTs. In fact, vegetables as well as fruits are known to provide several important health benefits (26). The dietary intake of antioxidant nutrients, as well as fruit and vegetable consumption, may reduce oxidative stress, once they are able to eliminate free radicals in a direct way, as is the case of vitamins, or in an indirect way, through minerals, which act as co-factors of antioxidant enzymes (27). Nevertheless, several pollutants can be absorbed by diet (28-31), and even if it is balanced, to date, the balance between benefits and risks due to the ingestion of contaminated food has been poorly characterized (32). 

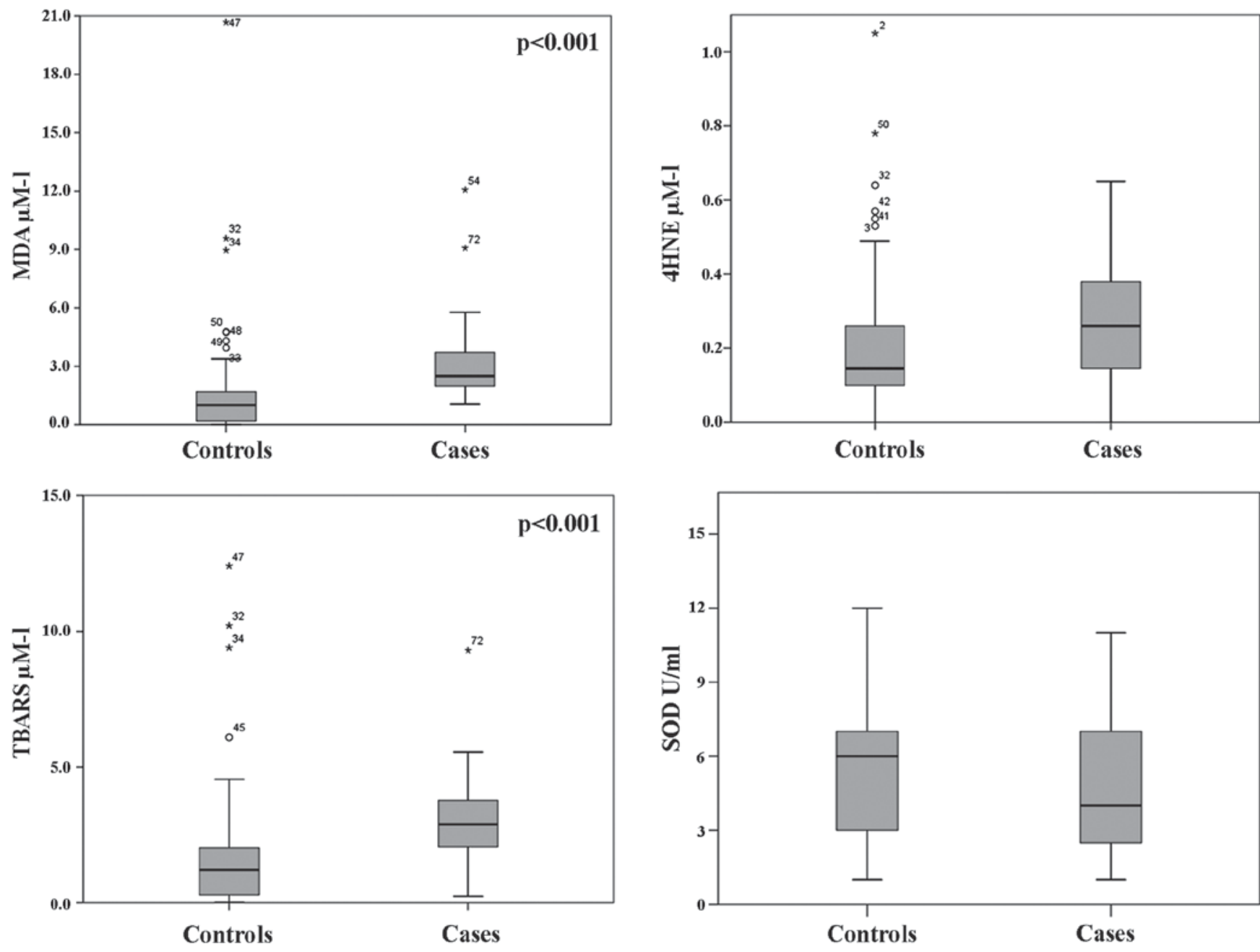

Figure 2. Box-plot of oxidative stress and oxidative defense parameters, detected in blood samples of the cases and the control group.

With regard to the toxic metal investigation, the highest levels of $\mathrm{Pb}$ were found in DVTs. In human blood, $\sim 99 \%$ of the lead is found in the erythrocytes, leaving $\sim 1 \%$ in the plasma and serum (33), indicating that erythrocytes could be an important target of lead toxicity in the cardiovascular system. $\mathrm{Pb}$ can increase thrombin generation and accelerating the coagulation process by tissue factor in plasma. $\mathrm{Pb}$ interferes with normal red blood cell formation by inhibiting important enzymes, inhibits SOD and reduces glutathione levels, increasing erythrocyte vulnerability to oxidative stress (34). In association with DVTs, $\mathrm{Pb}$ decreases the plasminogen activator antigen (t-PA:Ag), increasing the production of this inhibitor (PAI-1). Plasminogen degrades many blood proteins, and in particular the fibrin of thrombus. Its absence reduces fibrinolysis and therefore favors DVTs (35). In our patients $\mathrm{Pb}$ could have a role in the pathogenesis of DVTs, determining alterations in the erythrocyte membrane and their adhesiveness to the endothelium. It indirectly reduces the antioxidant defense mechanisms, exposing the endothelium to radicals and leading to endothelial dysfunction.

The $\mathrm{Pb}$ exposure can be caused by atmospheric pollution $(36,37)$, which is associated with alterations of physiological balance related to cardiovascular health such as inflammation, hypercoagulability, thrombosis, vascular dysfunction of the autonomic nervous system and atherosclerosis. The experi- mental results of the studies carried out by other authors indicate that long-term exposure (years or decades) to air pollutants contributes to pulmonary (38) and systemic oxidative stress, inflammation, atherosclerosis and increased risk of ischemic heart disease and death (5). The short-term exposure (days or weeks) favors the risk of acute coronary syndrome due to atherosclerotic plaque rupture and thrombosis $(39,40)$. Furthermore, air pollution has been associated with CVDs (heart failure, stroke, arrhythmias and cardiac dead) (41) and a few recent studies indicate that air pollutants can play a role in the DVT risk (2).

Arterial and venous thrombosis are commonly considered two distinct diseases, to date a growing body of evidence indicate several pathophysiological links. There are many common risk factors such as age, obesity, metabolic syndrome and most recently, the negative effect of short or prolonged exposure to air contaminants (42-44).

It is known that air pollution plays a role on hypercoagulative condition. Consequently, there is a link between pollutants and venous thrombosis.

However, we possess robust knowledge concerning the role of air pollution on arterial thrombosis, while its role on venous thrombosis is still unclear.

Since our study showed an important significance on public health due to the high risk of venous thromboembolic 
disease (45), it has a limit concerning the number of recruited subjects.

A larger amount of high-quality scientific experimental data are required to confirm our preliminary results and to correlate the atmospheric pollution with the residential areas of the recruited subjects. The results of this research are an important step in the understanding of the relationship between lifestyles, environmental pollution and venous thromboembolism, deepening the knowledge on their bond through the study of oxidative stress.

\section{Acknowledgements}

This study was supported by the Department of Clinical and Experimental Medicine, University of Catania and the Department of Medical, Surgical Sciences and Advanced Technologies, 'G.F. Ingrassia' Hygiene and Public Health, University of Catania.

\section{References}

1. Goldhaber SZ: Pulmonary embolism thrombolysis: A clarion call for international collaboration. J Am Coll Cardiol 19: 246-247, 1992

2. Baccarelli A, Martinelli I, Zanobetti A, Grillo P, Hou LF, Bertazzi PA, Mannucci PM and Schwartz J: Exposure to particulate air pollution and risk of deep vein thrombosis. Arch Intern Med 168: 920-927, 2008.

3. Franchini M, Guida A, Tufano A and Coppola A: Air pollution, vascular disease and thrombosis: Linking clinical data and pathogenic mechanisms. J Thromb Haemost 10: 2438-2451, 2012.

4. Franchini M and Mannucci PM: Particulate air pollution and cardiovascular risk: Short-term and long-term effects. Semin Thromb Hemost 35: 665-670, 2009.

5. Franchini M and Mannucci PM: Thrombogenicity and cardiovascular effects of ambient air pollution. Blood 118: 2405-2412, 2011.

6. Signorelli SS, Fiore V, Puccia G, Mastrosimone G and Anzaldi M Thrombophilia in patients with lower limb deep veins thrombosis (LDVT). Results of a monocentric survey on 103 consecutive outpatients. Clin Appl Thromb Hemost 20: 589-593, 2014.

7. Fiore M, Ledda C, Rapisarda V, Sentina E, Mauceri C, D'Agati P, Oliveri Conti G, Serra-Majem L and Ferrante M: Medical school fails to improve Mediterranean diet adherence among medical students. Eur J Public Health 25: 1019-1023, 2015.

8. Agodi A, Barchitta M, Valenti G, Quattrocchi A, Marchese AE, Oliveri Conti G, Fallico R, Sciacca S and Ferrante M: Dietary folate intake and blood biomarkers reveal high-risk groups in a Mediterranean population of healthy women of childbearing potential. Ann Nutr Metab 63: 179-185, 2013.

9. Sciacca S and Oliveri Conti G: Mutagens and carcinogens in drinking water. Med J Nutrition Metab 2: 157-162, 2009.

10. World Health Organisation: Global status report on noncommunicable diseases 2010. World Health Organisation, Geneva, 2010

11. Goldhaber SB: Trace element risk assessment: Essentiality vs. toxicity. Regul Toxicol Pharmacol 38: 232-242, 2003.

12. Jomova $\mathrm{K}$ and Valko $\mathrm{M}$ : Advances in metal-induced oxidative stress and human disease. Toxicology 283: 65-87, 2011.

13. Santo SS, Sergio N, Luigi DP, Giuseppe M, Margherita F, Gea OC, Roberto F, Gabriella C, Giuseppe P and Massimiliano A: Effect of PLC on functional parameters and oxidative profile in type 2 diabetes-associated PAD. Diabetes Res Clin Pract 72: 231-237, 2006.

14. Signorelli SS, Fatuzzo P, Rapisarda F, Neri S, Ferrante M, Oliveri Conti G, Fallico R, Di Pino L, Pennisi G, Celotta G, et al: A randomised, controlled clinical trial evaluating changes in therapeutic efficacy and oxidative parameters after treatment with propionyl L-carnitine in patients with peripheral arterial disease requiring haemodialysis. Drugs Aging 23: 263-270, 2006.

15. Reguig S, Bouanane S, Merzouk H, Soufi N and Merzouk S: Oxidative stress and thrombotic disorders: Study in patients with venous thromboembolism. Int J Health Sci Res 6: 185-194, 2016.
16. Zhang X, Staimer N, Gillen DL, Tjoa T, Schauer JJ, Shafer MM, Hasheminassab S, Pakbin P, Vaziri ND, Sioutas C, et al: Associations of oxidative stress and inflammatory biomarkers with chemically-characterized air pollutant exposures in an elderly cohort. Environ Res 150: 306-319, 2016.

17. Busch CJ and Binder CJ: Malondialdehyde epitopes as mediators of sterile inflammation. Biochim Biophys Acta: Jun 26, 2016 (Epub ahead of print).

18. Papac-Milicevic N, Busch CJ and Binder CJ: Malondialdehyde epitopes as targets of immunity and the implications for atherosclerosis. Adv Immunol 131: 1-59, 2016.

19. Esterbauer $\mathrm{H}$ and Zollner $\mathrm{H}$ : Methods for determination of aldehydic lipid peroxidation products. Free Radic Biol Med 7: 197-203, 1989.

20. Uriu-Adams JY and Keen CL: Copper, oxidative stress, and human health. Mol Aspects Med 26: 268-298, 2005.

21. Chambers JC, Haskard DO and Kooner JS: Vascular endothelial function and oxidative stress mechanisms in patients with Behçet's syndrome. J Am Coll Cardiol 37: 517-520, 2001.

22. Brawn K and Fridovich I: Superoxide radical and superoxide dismutases: Threat and defense. Acta Physiol Scand (Suppl) 492: 9-18, 1980.

23. Sinet PM and Garber P: Inactivation of the human $\mathrm{CuZn}$ superoxide dismutase during exposure to $\mathrm{O}_{2}$ and $\mathrm{H}_{2} \mathrm{O}_{2}$. Arch Biochem Biophys 212: 411-416, 1981.

24. Harzallah O, Kerkeni A, Baati T and Mahjoub S: Oxidative stress: Correlation with Behçet's disease duration, activity and severity. Eur J Intern Med 19: 541-547, 2008.

25. Meng YY, Trachtenburg J, Ryan US and Abendschein DR: Potentiation of endogenous nitric oxide with superoxide dismutase inhibits platelet-mediated thrombosis in injured and stenotic arteries. J Am Coll Cardiol 25: 269-275, 1995.

26. Ames BN, Shigenaga MK and Hagen TM: Oxidants, antioxidants, and the degenerative diseases of aging. Proc Natl Acad Sci USA 90: 7915-7922, 1993.

27. Alissa E and Ferns G: Functional foods and nutraceuticals in the primary prevention of cardiovascular diseases. J Nutr Metab 2012: 569486, 2012.

28. Conte F, Copat C, Longo S, Conti GO, Grasso A, Arena G, Brundo MV and Ferrante M: First data on trace elements in Haliotis tuberculata (Linnaeus, 1758) from southern Italy: Safety issues. Food Chem Toxicol 81: 143-150, 2015.

29. Conti GO, Copat C, Ledda C, Fiore M, Fallico R, Sciacca S and Ferrante M: Evaluation of heavy metals and polycyclic aromatic hydrocarbons (PAHs) in Mullus barbatus from Sicily Channel and risk-based consumption limits. Bull Environ Contam Toxicol 88: 946-950, 2012.

30. Copat C, Bella F, Castaing M, Fallico R, Sciacca S and Ferrante M: Heavy metals concentrations in fish from Sicily (Mediterranean Sea) and evaluation of possible health risks to consumers. Bull Environ Contam Toxicol 88: 78-83, 2012.

31. Copat C, Vinceti M, D'Agati MG, Arena G, Mauceri V, Grasso A, Fallico R, Sciacca S and Ferrante M: Mercury and selenium intake by seafood from the Ionian Sea: A risk evaluation. Ecotoxicol Environ Saf 100: 87-92, 2014.

32. Copat C, Arena G, Fiore M, Ledda C, Fallico R, Sciacca S and Ferrante M: Heavy metals concentrations in fish and shellfish from eastern Mediterranean Sea: Consumption advisories. Food Chem Toxicol 53: 33-37, 2013.

33. Rabinowitz MB: Toxicokinetics of bone lead. Environ Health Perspect 91: 33-37, 1991.

34. Hossain S, Bhowmick S, Islam S, Rozario L, Jahan S, Hassan M, Sarkar M, Choudhury BK, Ahmed S and Shahjalal H: Oral administration of Ganoderma lucidum to lead-exposed rats protects erythrocytes against hemolysis: Implicates to anti-anemia. Evid Based Complement Alternat Med 2015: 463703, 2015.

35. Kaji T, Yamamoto C, Sakamoto $M$ and Kozuka H: Inhibitory effect of lead on the release of tissue plasminogen activator from human vascular endothelial cells in culture. Toxicology 73: 219-227, 1992.

36. Sun Y,Zhuang G, Zhang Z, Wang Y and Zhuang Y: Characteristics and sources of lead pollution after phasing out leaded gasoline in Beijing. Atmos Environ 40: 2973-2985, 2016.

37. Sangani RG, Soukup JM and Ghio AJ: Metals in air pollution particles decrease whole-blood coagulation time. Inhal Toxicol 22: 621-626, 2010.

38. Ghanbari Ghozikali M, Heibati B, Naddafi K, Kloog I, Oliveri Conti G, Polosa R and Ferrante M: Evaluation of chronic obstructive pulmonary disease (COPD) attributed to atmospheric $\mathrm{O}_{3}, \mathrm{NO}_{2}$, and $\mathrm{SO}_{2}$ using Air Q Model (2011-2012 year). Environ Res 144 (Pt A): 99-105, 2016. 
39. Bind MA, Baccarelli A, Zanobetti A, Tarantini L, Suh H, Vokonas P and Schwartz J: Air pollution and markers of coagulation, inflammation, and endothelial function: Associations and epigene-environment interactions in an elderly cohort. Epidemiology 23: 332-340, 2012.

40. Madrigano J, Baccarelli A, Mittleman MA, Wright RO, Sparrow D, Vokonas PS, Tarantini L and Schwartz J: Prolonged exposure to particulate pollution, genes associated with glutathione pathways, and DNA methylation in a cohort of older men. Environ Health Perspect 119: 977-982, 2011.

41. Mills NL, Donaldson K, Hadoke PW, Boon NA, MacNee W, Cassee FR, Sandström T, Blomberg A and Newby DE: Adverse cardiovascular effects of air pollution. Nat Clin Pract Cardiovasc Med 6: 36-44, 2009
42. Piazza G and Goldhaber SZ: Venous thromboembolism and atherothrombosis: An integrated approach. Circulation 121: 2146-2150, 2010

43. Ageno W, Becattini C, Brighton T, Selby R and Kamphuisen PW: Cardiovascular risk factors and venous thromboembolism: A meta-analysis. Circulation 117: 93-102, 2008.

44. Prandoni P: Venous and arterial thrombosis: Two aspects of the same disease? Clin Epidemiol 1: 1-6, 2009

45. Signorelli SS, Fiore V, Ruggieri M and Basile A: Acute deep vein thrombosis (DVT) of the lower limbs in a 32-year-old man with chronic hypoplasia of the inferior vena cava (HIVC) without risk factors. Intern Emerg Med 11: 273-275, 2016. 